\title{
CONOCIMIENTO EMOCIONAL, COMPLEJIDAD VIVENCIAL Y RESILIENCIA MATEMÁTICA. TRES FACETAS PARA EL AFECTO EN EDUCACIÓN MATEMÁTICA
}

\author{
EMOTIONAL KNOWLEDGE, EXPERIENTIAL COMPLEXITY AND MATHEMATICAL \\ RESILIENCE. THREE FACETS FOR AFFECT IN MATHEMATICS EDUCATION \\ CONHECIMENTO EMOCIONAL, COMPLEXIDADE EXPERIENCIAL E RESILIÊNCIA \\ MATEMÁTICA. TRÊS FACETAS DA AFETIVIDADE NA EDUCAÇÃO MATEMÁTICA
}

\author{
Oswaldo Jesús Martínez-Padrón ${ }^{1}$ iD \\ Jorge Iván Ávila-Contreras 2 iD \\ María S. García-González 3 iD \\ ${ }^{1}$ Universidad Técnica del Norte, Ibarra, Ecuador \\ ${ }^{2}$ Universidad Metropolitana de Ciencias de la Educación, Santiago, Chile \\ ${ }^{3}$ Universidad Autónoma de Guerrero, Chilpancingo de los Bravo, México \\ Recibido: 02/04/2021 - Aceptado: 11/05/2021 - Publicado: 01/12/2021 \\ Remita cualquier duda sobre esta obra a: María S. García-González. \\ Email:msgarcia@uagro.mx
}

\begin{abstract}
RESUMEN
Este artículo reporta reflexiones emanadas de tres conferencias vinculadas al Dominio Afectivo en Educación Matemática, efectuadas en el seminario de Formación de Investigadores en Temas Contemporáneos de la Educación Matemática (FITCEM), organizado por la Asociación Aprender en Red. En primer lugar, se sintetizan aspectos relacionados con el Dominio Afectivo desde la postura de McLeod, perspectiva cognitiva bastante utilizada en Educación Matemática. Posteriormente se centra la atención en las emociones, uno de los tres descriptores básicos del modelo de McLeod. El abordaje hacia las emociones se realiza a partir de dos posturas, la noción de conocimiento emocional y la noción de complejidad vivencial: la primera centrada en lo cognitivo y la segunda desde un punto de vista principalmente configurativo y vivencial, más que cognitivo. Finalmente, se atiende a la resiliencia matemática y a su consideración como un componente pertinente para el estudio del afecto en Educación Matemática, dada las características de esta disciplina y el imaginario colectivo racionalista que muchas veces existe en la sociedad cuando se piensa en la actividad matemática.
\end{abstract}

Palabras clave: Conocimiento Emocional; Complejidad Vivencial; Resiliencia Matemática; Educación 
Matemática; Dominio Afectivo.

\begin{abstract}
This paper reports reflections emanating from three talks related to the Affective Domain in Mathematics Education held in the seminar Formación de Investigadores en Temas Contemporáneos de la Educación Matemática (FITCEM), organized by the Aprender en Red Association. In the first place, we expose aspects related to the Affective Domain from McLeod's perspective, a cognitive point of view widely used in Mathematics Education. Then we focus on emotions, one of the three basic descriptors of McLeod's model. The approach to emotions is carried out from two positions, the notion of emotional knowledge, and the notion of experiential complexity: the first focuses on the cognitive and the second from a mainly configurative and experiential point of view rather than cognitive. Finally, we talk about mathematical resilience and its consideration as a relevant component for the study of affect in Mathematics Education, given the characteristics of this discipline and the rationalist collective imagination that often exists in society when thinking about mathematical activity.
\end{abstract}

Keywords: Emotional Knowledge; Experiential Complexity; Mathematical Resilience; Mathematics Education; Affective Domain.

\title{
RESUMO
}

Este artigo relata reflexões emanadas de três palestras relacionadas ao Domínio Afetivo em Educação Matemática, realizadas no seminário Formação de Investigadores em Temas Contemporâneos da Educação Matemática (FITCEM), organizado pela Asociación Aprender en Red. Em primeiro lugar, sintetizam-se aspectos relacionados ao Domínio Afetivo a partir da posição de McLeod, perspectiva cognitiva amplamente utilizada na Educação Matemática. Posteriormente, coloca-se o foco nas emoções, um dos três descritores básicos do modelo de McLeod. A abordagem às emoções é realizada a partir de duas posições, a noção de conhecimento emocional e a noção de complexidade experiencial: a primeira com foco no cognitivo e a segunda de um ponto de vista principalmente configurativo e experiencial, em lugar de cognitivo. Por fim, aborda-se a resiliência matemática e a sua consideração como componente relevante para o estudo do afeto na Educação Matemática, dadas as características desta disciplina e o imaginário coletivo racionalista que muitas vezes existe na sociedade quando se pensa na atividade matemática.

Palavras-chave: Conhecimento Emocional; Complexidade Experiencial; Resiliência Matemática; Educação Matemática; Domínio Afetivo.

\section{DOMINIO AFECTIVO EN EDUCACIÓN MATEMÁTICA}

En Educación Matemática existe una línea de investigación que se dedica a estudiar aspectos relacionados con el sentir de los que aprenden y enseñan matemáticas, la cual recibe el nombre de Dominio Afectivo o Afecto, cuyo origen se debe al educador matemático norteamericano Douglas $\mathrm{B}$. McLeod quien, en la década de los 90's, basado en la revisión de trabajos de corte más afectivo que cognitivo, lo definió como un extenso rango de sentimientos y estados de ánimo que son generalmente considerados como algo diferente de la pura cognición, y reconoció en éste tres descriptores básicos: las actitudes, las emociones y las creencias (McLeod, 1992). Con el paso del tiempo, se han incluido otros constructos como la motivación y los valores (DeBellis \& Goldin, 2006). 
Los resultados de investigación sobre estos descriptores básicos han mostrado que, junto a la cognición, el afecto juega un papel relevante en el aprendizaje de las matemáticas. Por ejemplo, se sabe que las creencias de los estudiantes sobre las matemáticas influyen en la forma en que las aprenden (Ayebo \& Mrutu, 2019; Callejo \& Vila, 2003; Pehkonen \& Törner, 1996). En el caso de las emociones, se ha evidenciado que éstas influyen de manera directa en las actividades específicas que realiza el estudiante en la clase de matemáticas, siendo la resolución de problemas el caso más documentado. Por ejemplo, el estudiante puede presentar bloqueos que le provoquen frustración o miedo a volver a enfrentarse a un problema (Lewis, 2013; Martínez-Sierra \& García-González, 2014, 2016). Un resultado relevante sobre las actitudes hacia las matemáticas es que su formación depende del nivel escolar de los estudiantes, de acuerdo con Hidalgo et al. (2004); las actitudes hacia las matemáticas no se consolidan en edades tempranas sino a finales de la escuela primaria (6-12 años) y durante la escuela secundaria (12-15 años).

Pese a estos avances del Dominio Afectivo que muestran su relevancia para la Educación Matemática, su desarrollo se ha visto criticado en dos aspectos principales: la falta de un marco teórico único para el estudio de sus constructos y la falta de instrumentos para medirlos (ver, por ejemplo, Di Martino \& Zan, 2001; Gómez-Chacón, 2010). Debido a que los constructos que definen al Afecto son propios de la Psicología, cuando se estudian desde la Educación Matemática se hacen algunas adaptaciones y algunos instrumentos de medida son exportados, como es el caso de la medición de actitudes hacia las matemáticas (Auzmendi, 1992), donde suelen utilizarse escalas tipo Likert. De esta manera, estos aspectos se han convertido en puntos pendientes en la agenda del Dominio Afectivo.

Otro punto pendiente en esta agenda es el estudio de los estados afectivos y cognitivos de manera simultánea (Middleton et al., 2018; Zan et al., 2006), pues hasta ahora existe un énfasis en estudiar las relaciones del estudiante con la propia clase de matemáticas, con los contenidos y con la resolución de problemas, pero se ha dejado de lado la relación del afecto con los procesos cognitivos que desencadenan las matemáticas, como el razonamiento matemático, por citar alguno. A ellos se une el estudio de la regulación emocional, que propone Hannula (2020). De acuerdo con este autor, a la fecha, ya existe un conocimiento general, aunque no profundo, de las emociones en la clase de matemáticas, y ahora el desafío se encuentra en poder regular las emociones que afectan a docentes y estudiantes.

Con el presente escrito se invita al lector a reflexionar sobre el fenómeno emocional en la enseñanza y el aprendizaje de las matemáticas. Se comparten dos acercamientos para hacerlo, el conocimiento emocional y la complejidad vivencial, el primero dirigido principalmente a un acercamiento a la regulación de las emociones y, el segundo, para evidenciar la complejidad de la ocurrencia de una emoción, con respecto a la multiplicidad de elementos que intervienen en ella, tomando en cuenta la vivencia de quien la experimenta (p.e., la faceta histórico-biográfica-personal, las creencias, la relación con las personas o sucesos, entre otros). Finalmente, se resalta la importancia de la resiliencia matemática en el aula de clase, tanto para el docente como para el estudiante, reconociéndose como un elemento pertinente de analizar en el ámbito de la Educación Matemática. 


\section{CONOCIMIENTO EMOCIONAL}

Si hablamos de emociones, la dificultad principal a la que nos topamos es definirlas, pero experimentarlas no tiene mayor complejidad. Todos los seres humanos experimentamos diariamente emociones en las múltiples actividades que realizamos, y la clase de matemáticas no es la excepción. Sin embargo, no siempre somos conscientes de las situaciones que las desencadenan y más aún, de dar el nombre correcto a la emoción que sentimos. De acuerdo con García-González et al. (2021), desde la postura de la Teoría de la Estructura Cognitiva de las Emociones (llamada Teoría OCC), una emoción es el resultado de la valoración que el estudiante hace ante determinado evento (p.e., la clase de matemáticas), algún agente (p.e., el docente de matemáticas) o determinado objeto (la matemática como asignatura). Este conjunto de situaciones recibe el nombre de situación desencadenante de la emoción. La valoración se expresa mediante una palabra que recibe el nombre de palabra emocional.

Para aclarar lo anterior, presentamos la narrativa de un estudiante al que se le cuestionó sobre las emociones que experimenta en su clase de matemáticas (García-González et al., 2021).

Estudiante G1-H5: He experimentado emoción [palabra emocional] al acreditar matemáticas [situación desencadenante], y en ocasiones tensión [palabra emocional] porque he sentido que no voy a pasar la materia [previsión-situación desencadenante].

Siguiendo los lineamientos de la Teoría OCC, G1-H5 usa la propia palabra emoción para describir la valoración de la emoción experimentada. Comúnmente, quienes no poseen un vocabulario emocional amplio tienden a usar la misma palabra emoción para expresar una emoción positiva, y la situación desencadenante de su emoción es acreditar la asignatura de matemáticas.

Por nuestra parte, consideramos que como docentes o estudiantes de matemáticas no es necesario poseer una definición de lo que es la emoción, pero sí es necesario conocernos emocionalmente; es decir, deberíamos ser capaces de identificar aquello que nos hace experimentar la emoción (situación desencadenante) y el término correcto de nombrar eso que sentimos (palabra emocional). Por ello, proponemos el término conocimiento emocional (García-González, 2020) para referirnos a la información que poseemos sobre nuestras emociones durante la enseñanza o el aprendizaje de las matemáticas. Para poseer este conocimiento emocional es necesario desarrollar las siguientes

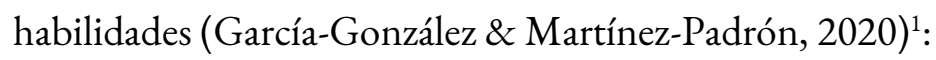

\footnotetext{
${ }^{1}$ Aclaramos al lector que el desarrollo de estas habilidades requiere de entrenamiento y que existen técnicas que pueden ayudarnos a adquirirlas. Por ejemplo, García-González y Martínez-Padrón (2020) proponen el uso del dibujo y de la narrativa. Tocante a la narrativa, la tercera autora de este escrito la ha implementado en talleres con docentes y estudiantes en los que se persigue el desarrollo de las primeras 5 habilidades listadas anteriormente.
} 
1. Reconocer lo que sentimos: las emociones son parte de nuestra naturaleza humana.

2. Reconocer qué sentimos: ser capaces de reconocer qué emoción experimentamos ante determinada situación.

3. Concretar, con claridad, la palabra que representa la emoción que realmente sentimos, por ejemplo, no es lo mismo sentir miedo que pavor, sabiendo que este último da cuenta de una intensidad mayor que el miedo.

4. Reconocer qué situación desencadena eso que sentimos.

5. Distinguir las emociones negativas de las positivas.

6. Regular las emociones que experimentamos, siendo capaces de actuar en consecuencia.

En la Tabla 1 se muestra un protocolo de preguntas que se pueden usar para indagar sobre las emociones en la clase de matemáticas. Todas las preguntas están pensadas para que arrojen información sobre experiencias emocionales. Aclaramos que son varias las investigaciones que han mostrado el potencial de estas preguntas (ver por ejemplo Martínez-Sierra \& García-González, 2014, 2016).

\section{Tabla 1}

Cuestionario para indagar emociones

\begin{tabular}{|c|c|}
\hline Objetivo & Pregunta \\
\hline $\begin{array}{l}\text { Que la persona describa sus } \\
\text { emociones en matemáticas }\end{array}$ & $\begin{array}{l}\text { 1. ¿Qué emociones o sentimientos experimenta en matemáticas?, ¿Por qué } \\
\text { experimenta todo eso? }\end{array}$ \\
\hline $\begin{array}{l}\text { Que la persona exprese palabras } \\
\text { emocionales }\end{array}$ & $\begin{array}{l}\text { 2. ¿Cuáles son las principales experiencias positivas que ha tenido en } \\
\text { matemáticas? } \\
\text { 3. ¿Cuáles son las principales experiencias negativas que ha tenido en } \\
\text { matemáticas? }\end{array}$ \\
\hline $\begin{array}{l}\text { Que la persona exprese situaciones } \\
\text { desencadenantes }\end{array}$ & $\begin{array}{l}\text { 4. ¿En qué circunstancias y situaciones ha experimentado felicidad o } \\
\text { alegría en matemáticas? } \\
\text { 5. ¿En qué circunstancias o situaciones ha experimentado tristeza o pesar } \\
\text { en matemáticas? }\end{array}$ \\
\hline
\end{tabular}

La pregunta 1 cuestiona directamente sobre las emociones experimentadas, y aunque conceptualmente las palabras emoción y sentimiento no son sinónimas, una distinción es su temporalidad (Bisquerra, 2009); en el lenguaje coloquial se usan como tal, por ello el sentido de la pregunta es válido. La distinción conceptual se usa al momento del análisis; si alguien dijera que siente amor por las matemáticas, la palabra amor no se considera una emoción, sino más bien un sentimiento. Las preguntas 2 y 3 pretenden detonar palabras emocionales, por ello en su planteamiento se piden 
experiencias positivas y negativas; se espera que, al contar sus experiencias, las personas mencionen palabras emocionales. Las preguntas 4 y 5 tienen el objetivo de que las personas expresen situaciones desencadenantes, por lo que aparecen dos tipos de emociones con valencia distinta. Se usan las palabras felicidad y alegría como representantes de palabras emocionales positivas, y tristeza y pesar como ejemplo de dos emociones negativas.

Con el protocolo anterior, no es la intención limitar al docente o al estudiante a las palabras emocionales que ahí aparecen (por ejemplo, que solo hable de alegría, felicidad, tristeza o pesar), porque las preguntas 1, 2 y 3 dejan el campo abierto para que se hable de los diferentes tipos de emociones experimentadas. Como señalamos antes, estas preguntas se han usado en investigaciones anteriores y en talleres impartidos por la tercera autora de este escrito, siendo que hasta ahora se ha encontrado evidencia de experiencias emocionales que prueban su funcionalidad.

Una vez que se han respondido las preguntas del Cuadro 1, se propone identificar en la narrativa las palabras emocionales y la situación desencadenante de la emoción, lo que ayudará a confrontar el conocimiento emocional que se posee. A manera de ejemplo, presentamos los siguientes casos de docentes e invitamos al lector a identificar en ellos las emociones y situaciones desencadenantes de éstas.

Profesor 1: Experimento felicidad cuando los estudiantes me cuentan lo que
han aprendido, para esto realizo lluvia de ideas o mapas conceptuales, también
cuando los alumnos resuelven una situación didáctica contextualizada.

Profesora 2: Principalmente al estar frente al grupo o realizar diversas actividades académicas experimento alegría y amor. Algunas otras emociones que he experimentado ban sido satisfacción, empatia, paciencia y algunas otras veces ansiedad y desesperación.

Profesor 3: Como docente he experimentado miedo, nerviosismo, al inicio del periodo o semestre porque son nuevos alumnos... a veces experimento enojo $y$ frustración, pero, en su mayoria, siento felicidad.

En el caso del Profesor 1, la emoción que identificamos es la felicidad y la situación desencadenante es el aprendizaje y la resolución de actividades. Por su parte la Profesora 2 habla de la alegría por estar frente al grupo y realizar actividades académicas. En su caso, el Profesor 3 refiere al miedo que tiene como situación desencadenante los nuevos alumnos y el inicio de semestre. ¿Coincide el lector con nuestra interpretación? Aclaramos que en el caso de la Profesora 2, la palabra amor no es una palabra emocional: el amor es un sentimiento, no una emoción. Por su vez, en el caso del Profesor 3 no hay suficiente información para conocer lo que desencadena su enojo, su frustración o su felicidad. En síntesis, este ejercicio nos permite reflexionar sobre nuestra capacidad para comunicar nuestras emociones de manera escrita y a valorar si verdaderamente poseemos un conocimiento emocional genuino. 
Para terminar esta sección, nos gustaría enfatizar en la importancia que tienen las emociones en la enseñanza y el aprendizaje de las matemáticas. Las emociones influyen en nuestras decisiones y actuaciones. Por ejemplo, en el caso de los estudiantes, el estrés frecuente por no ser capaz de resolver un problema, a largo plazo, puede desencadenar en una actitud de rechazo hacia las matemáticas y a formar la creencia de que no se es bueno en matemáticas. En el caso de los docentes, una emoción negativa reiterada puede conducir al rechazo por la enseñanza. A manera de ejemplo, observe la siguiente intervención de una docente de matemáticas de secundaria.

Profesora 5: Cuando los alumnos no cumplen con las tareas o actividades asignadas me molesto y pienso si realmente la docencia es para lo que estoy hecha... además, hay algunos alumnos que por su actitud negativa llegan a incomodarme y no me agrada entrar a ese grupo. Por el contrario, hay alumnos muy respetuosos y trabajadores, iabi si me gusta ser docente!

\section{COMPLEJIDAD VIVENCIAL}

Somos seres emocionales y racionales a la vez (Casassus, 2015; Morín, 1999), por ende, lo que cada persona vivencia - en el sentido de aquello que experimenta como ser único e intransferible en cada momento de la vida- es inseparable de su experiencia emocional. Al aula de matemáticas en particular concurrimos con nuestro acervo experiencial (mediato e inmediato) lo que -en conjunto con lo que acontece directamente en la situación de aula- coadyuva a que emerjan diversas emociones en la experiencia de involucrarse en el estudio de las matemáticas. A fin de aproximarse a dilucidar diferentes flujos y trayectorias implicados en la ocurrencia de una emoción, Ávila (2018) acuña la noción de complejidad vivencial y distingue entre emoción por emergencia y emoción por concurrencia:

Una emoción emerge en una persona cuando al vivenciar ésta una situación que la involucra, cobran forma aspectos configurativos que caracterizan esa emoción, principalmente, a propósito de aquello que está aconteciendo en ese momento (...) una emoción concurre en la persona cuando ante una situación que la involucra emerge la emoción, pero esta vez, más entrelazada a lo que porta desde el acervo experiencial. (Ávila, 2018, p. 116)

A manera de ejemplo, tomamos las siguientes narrativas de escolares de tercer año de educación primaria, que refieren a las emociones que sienten previo a una evaluación escrita en la clase de matemáticas (Vejar-Barra \& Ávila-Contreras, 2020, pp. 58-59):

Estudiante 4: [Triste] Porque me pegaron en el recreo jugando a la pelota.

Estudiante 30: Estoy triste porque no quieren jugar conmigo en el recreo. 
Estudiante 19: [Nerviosa - preocupada] Porque cuando no me sé la prueba, después mi mamá se enoja.

Estudiante 20: [Asustada - nerviosa] Porque no estudié y si me va mal me van a retar y no iré al Disney once one.

Estas narrativas ilustran que el cotidiano entra al aula y forma parte de aquello que configura a una emoción, en estos casos por concurrencia (tristeza, nerviosismo, preocupación, susto) ya sea como un aspecto ligado a los momentos inmediatamente previos a su ocurrencia (lo vivenciado en el recreo) o también ligado a lo que ya forma parte de sus vivencias y acervo experiencial (presión de los padres por la obtención de buenas calificaciones).

Ahora bien, cuando se está en la prueba de matemática propiamente tal, la estructura, la forma de la prueba, el ambiente, entre otros, generan a su vez emociones con un carácter de emergencia. Sin embargo, en ese momento experiencial del estar rindiendo la prueba, la presencia de las emociones concurrentes (tristeza por lo acontecido en el recreo, nerviosismo, preocupación o susto por la presión de los padres) se entrelaza también con la vivencia estudiantil.

Ávila (2018) en tanto reporta emociones por emergencia y concurrencia que confluyen en un curso de cálculo, vinculadas al imaginario colectivo que se tiene de un profesor de cálculo:

Estudiante E2: Al saber que tenia que tomar cálculo, sentia miedo, pensaba que el profesor iba a ser ultra pesado, que iba a entrar con los libros, y que era materia, materia y materia, pero el primer dia me di cuenta que eso no sería asi (...) todo lo contrario, usted es una persona muy cercana con nosotros, se preocupa de cómo estamos, cómo nos sentimos con el ramo, con la universidad o con los compañeros, eso a mi me motiva mucho.

Estudiante E7: Éste es un Cálculo diferente a los demás (...) lo lógico es que la asignatura de Cálculo la dicte un profesor con muy poco carisma, serio, frio, al cual los alumnos le tengan miedo y un respeto sobrevalorado. iEsto es histórico! En casi todas las ingenierias, licenciaturas en matemática, pedagogias, física, etc. sucede esto. Esto sucede en casi todos los cursos de cálculo en este pais [Chile]. El ramo colador por excelencia, el terror de miles. Pero la clase que usted dicta es demasiado amena y divertida. Hay espacio para la interacción, para sonreir y para estudiar también (...) conversando con mis compañeros de cursos más avanzados, veo que bubo un excelente aprendizaje. Que dominan muy bien la materia. ¿Quémás sepuede pedir? ¡Esto es excelente! (...) Todo lo que yo observaba se contradice con esto. Porque su fórmula es efectiva, es una invitación cordial a intentar de hacer clases más dinámicas. 
El miedo se presenta en la asignatura de cálculo como una emoción concurrente relacionada principalmente con un imaginario colectivo que asocia al profesor de dicha asignatura con un estereotipo de severidad, frialdad, seriedad, un sujeto pasador de materia y distante de sus estudiantes. Sin embargo, va surgiendo una emoción de tipo emergente que puede asociarse a bienestar, alegría y confianza, esto al vivenciar en el aula clases con un profesor-persona, lo cual incluso se entrelaza y coadyuva a que emerja una componente motivacional favorable. En la segunda narrativa, se observa una emoción adicional, de tipo emergente-concurrente, asociada a la sorpresa, que confluye principalmente por un encuentro entre lo conocido por el estudiante (imaginario colectivo) y su contraposición experiencial con lo que ahora observa/vivencia en el aula ("Todo lo que yo observaba se contradice con esto").

Con la componente del cotidiano y considerando ideas nucleares de la perspectiva del pensamiento complejo (Morín, 1990), se acuña la noción de complejidad vivencial (Ávila, 2018) como una propuesta que busca generar una aproximación para el estudio de las emociones a partir del punto de vista de las vivencias de los sujetos, tomando en cuenta flujos y trayectorias que tienen como resultado la ocurrencia de una emoción en una persona, en particular, en el contexto formativo de la Educación Matemática.

El pensamiento complejo es una postura filosófica generada en la década de los noventa por el pensador francés Edgar Morín, con la que se genera un salto cualitativo con relación a cómo se concibe al ser humano. Morín (1999) resalta que la animalidad y la humanidad constituyen juntas nuestra condición humana y que el concepto de hombre tiene un doble principio: uno biofísico y otro psicosocio-cultural. En particular, distingue como parte constituyente de lo humano a bucles inseparables que se co-definen entre sí: mente/cerebro/cultura, razón/afecto/impulso e individuo/sociedad/planeta.

Según Morín, el pensamiento complejo no constituye una latitud fija del conocimiento, sino una travesía de descubrimientos infinitos. Hay tres principios que ayudan a pensar la complejidad: el principio dialógico, que apunta a mantener la dualidad en el seno de la unidad, asociando términos a la vez complementarios y antagonistas; el principio de recursividad organizacional, una idea que rompe con el pensamiento lineal de causa/efecto; en ésta, todo lo que es producido reentra sobre aquello que lo ha producido en un ciclo en sí mismo auto-constitutivo, auto-organizador y auto-productor; y, finalmente, el principio bologramático en la relación parte-todo, que apela a que no solamente la parte está en el todo, sino que el todo está en la parte. Con esto, se trasciende al reduccionismo que no ve más que las partes y al holismo que no ve más que el todo (Morín, 1990).

Con este posicionamiento, Ávila (2018) define a la complejidad vivencial como aquella complejidad "que se constituye entrelazada a la experiencia del humano al vivenciar lo humano, en la complejidad en que se encuentre inmerso" (p. 113). Al estar la persona inmersa en un fenómeno complejo y tener la facultad de vivenciar, emerge ese otro tipo de complejidad: la vivencial.

Una complejidad vivencial se da por ejemplo en el ser padre o ser madre, una experiencia inaccesible por mucho que se busque comprender o empatizar con respecto a ella, ya que en el momento de ser padre o ser madre cobra forma y enactúa -al decir de Varela (1990)- un mundo propio e 
intransferible. Puede buscarse valorar o entender lo más empáticamente posible dicha experiencia, pero se sigue actuando desde fuera de esa maternidad, de esa paternidad (como alguien que no ha sido padre o madre). La complejidad vivencial sería eso: vivirla, sentirla, haber pasado o estar pasando por dicha experiencia. En el caso del aula de matemáticas: ser estudiante, ser maestro. Cada vivencia estudiantil y del maestro o de quien se involucre en el aula se constituye como una complejidad vivencial en el sentido descrito, con interrelaciones, emociones, impulsos y comprensiones propias de lo que allí concurre y acontece (Ávila, 2018). Con base en lo anterior, se busca atender al estudio de las emociones considerando la arista vivencial de los sujetos.

Ávila y Díaz (2019) ilustran el caso de Rebeca, con el cual distinguen emociones que emergen y concurren en su educación secundaria, que la llevan posteriormente a decidir ser profesora de matemáticas. En el devenir de su decisión, se develan sentires intensos de amor, desaprobación, enojo y generosidad, entre otros.

Rebeca: En el colegio (...) [la otra niña mejor del curso] era como esa niña que sacaba en cara que ella era buena porque su mamá era profesora de matemática, entonces ella se quedaba con el conocimiento, asi como que jabh nooo yo soy la mejor! iPara ella! Y yo de lo poco, o mucho (...) si yo aprendia y estaba segura, yo era capaz de exponerme frente del curso con un plumón y iya chiquillas [niñas] asi se hace! iAsi yo lo hice! [...] ahi yo empecé a enseñar, entonces yo decia: 'iSi'! me gusta que el conocimiento que tengo repartirlo, no dejarlo para mi'(...) conmigo [mi mejor amiga] pasó matemática, entonces con ella también yo buscaba la forma de cómo enseñar lo que quizás para mi era obvio, pero para ella no, y empezaba a jugar (...) [con la otra niña mejor del curso] Nos comparaban, porque era entre comillas como yo piola [sencilla, humilde], mi mamá no tenía estudios [...] todos decian en el curso [por la otra niña] ipero bija de profesora quien noo pob! Seria el colmo que no supieras matemática si tu mamá es profe. Y yo no poh, mi mamá no era así, mi mamá era poquito lo que sabia, también me lo enseñaba, entonces yo siempre también tuve esa cosa de que si sé poquito y puedo transmitirlo lo bacia (...) iMe cargan las personas que son asi!! [por la otra niña] (...) para mi era como demostrarle que no porque ella sepa o sea la mejor significa que los otros se tienen que quedar abajo (...) Y yo no podia ser de las mejores, pero si queria que mis compañeras y mis amigas fueran las mejores, entonces... para mi era un liderazgo, era ser lider y ser jefe, una cosa asi, entonces yo con mis amigas si ellas no sabian, no eran las mejores, pero lograr algún cambio en ellas. Esta niña no, estaba preocupada de su propio cambio y yo no, si yo tenia que dejarme un recreo menos para estudiar con mis amigas yo lo hacia, ella no [...] Cuando hicimos los ensayos PSU [Prueba de Selección Universitaria que se da en Chile 
para postular a la universidad] también tuvo la competencia conmigo, y yo le gané, y yo ni siquiera por competencia, sino que di lo que yo sabia no más y fui el mejor puntaje del curso [...] entonces después al final cuando salió ¿Qué quieres ser? Y yo: 'quiero ser profe, lo mio es ser profe'. Y abi me pusieron, ya, pero jen quécampo? Y yo siempre he sido buena en matemática, era lo único que me consideraba buena en el colegio, y dije iya! de matemática.

Se ilustra aquí parte de una complejidad vivencial entrelazada con sus emociones, que visibilizan a un ser vivo que vivencia, sufre y se alegra, se impacta, se define y co-define continuamente (p.e. el amor y generosidad con sus amigas, el amor y modelo de vida de su madre, la rivalidad con la otra niña mejor del curso con una cosmovisión de mundo distinta a la suya). Más que una toma de decisión para ser profesora de matemáticas que pueda darse por una racionalidad externa y objetiva, ajena a sus vivencias, se trata de una decisión atravesada por una complejidad vivencial que abraza e involucra a la persona en su devenir vital.

\section{AFECTO Y RESILIENCIA MATEMÁTICA}

Cuando se mira al afecto desde una serie de constructos como los sistemas de creencias, emociones, actitudes (McLeod, 1992); motivaciones, valores (DeBellis \& Goldin, 2006), impulsos y sentimientos (Damasio, 2009) se puede dar cuenta de que los seres humanos somos afectivos por naturaleza, pero toda experiencia afectiva incluye conocimiento y acción (Quiroga, 2001), configurándose así un trinomio de dimensiones que se reclaman mutuamente $y$, por tanto, gradan rasgos característicos que permiten conocernos, proyectarnos en múltiples facetas de la vida, plantearnos fines y alcanzarlos.

Tales dimensiones no son desarticulables, por tanto, están presentes en todos aquellos procesos de resonancia afectiva aspectados, en este caso, por quienes protagonizan la clase de matemáticas, lugar donde suelen acontecer situaciones productoras no solo de felicidad (Profesor 1) y alegría (Profesor 2), sino de miedo, enojo y frustración (Profesor 3) o desagrado (Profesora 5), según lo indicado en secciones anteriores.

Otros docentes también fueron observados y entrevistados en un curso de matemáticas que constituía parte de la malla curricular que los formaba y profesionalizaba como docentes integradores para la Educación Primaria en Venezuela. A pesar de que la mayoría tenía muchos años enseñando contenidos matemáticos en las escuelas primarias, sin tener la titulación correspondiente, un importante número de casos manifestó aburrimiento, desagrado y aversión hacia las matemáticas, destacando que en esta situación privó su sistema de creencias, así como sus actitudes negativas hacia las matemáticas y hacia quienes las enseñan (Martínez-Padrón, 2008, 2016).

En relación con otros estudiantes de cursos de matemáticas, también se ha mencionado no solo la presencia de situaciones de miedo (como la emoción concurrente señalada en el Estudiante 2 en la sección anterior) sino de ansiedad, angustia o rabia manifestadas por otros, lo cual se compagina con el 
hecho que a muchos les resulta difícil participar en la clase y evitan cualquier interacción donde se les solicite razonamiento. Eso tiende a ocurrir ante el miedo de entrar en escena, existiendo muchos casos, según Johnston-Wilder y Lee (2014), que exhiben ansiedad en la clase de matemáticas.

Es notorio que las emociones siempre están involucradas y comprometidas en la vida de los protagonistas de la clase de matemáticas y comandan, prácticamente, todas las actividades allí desarrolladas (Martínez-Padrón, 2021), logrando materializarse hasta secuestros cognitivos (Goleman, 2006) propiciatorios de bloqueos en los estudiantes (García-González \& Martínez-Padrón, 2020; Martínez-Padrón, 2008, 2021). Si eso ocurre, es factible decantar un abanico de indefensiones (Seligman, 2006) que no permite reaccionar, favorablemente, ante la tarea de resolver un problema, lo cual representa una adversidad latente para muchos estudiantes de cursos de matemáticas (Martínez-Padrón, 2016, 2021). Eso invita a no dejar de lado este tipo de estimaciones, habida cuenta de saberse que, desde la neurobiología, consideran a las emociones y a los sentimientos como "clave para la formulación de principios y políticas capaces tanto de reducir las aflicciones como de aumentar la prosperidad de las personas" (Damasio, 2009, p. 14). Por ende, este es un tema insoslayable a tomarse en cuenta en la clase de matemáticas, en virtud de abrirse espacios para el tratamiento de tensiones no resueltas, incompetencias e indefensiones por parte de los estudiantes.

Para Seligman (2006), las indefensiones se manifiestan cuando las personas se enfrentan a situaciones negativas de las cuales no pueden huir o evadir. Sostiene que las mismas son aprendidas y pueden mantenerse así cambien algunas condiciones contextuales que les permitan concretar respuestas de escape. Situaciones similares se observan en sesiones de enseñanza que suelen ser precarias (Martínez-Padrón, 2021), bien porque pudieran estar henchidas de violencia o-entre otras razones- por estar desempeñadas por docentes cargados de incompetencias, inconscientes y conscientes, que no permiten desarrollar su labor en forma amena y productiva (Broadwell, 1969). Este último autor sostiene que, ante este tipo de situaciones, los estudiantes se aburren y no muestran interés alguno por desarrollar las competencias programadas en los cursos, tal como suele ocurrir en las clases de matemáticas (Martínez-Padrón, 2016, 2021), donde se pueden observar casos marcados por el uso de palabras ofensivas, despectivas o descalificadoras o por la presencia de acciones punitivas como las mostradas por Caballero-Jiménez y Espínola-Reyna (2016), quienes dan cuenta de una denuncia hecha a una profesora de matemáticas, ante el hecho de castigar a un niño de 7 años por no saberse, de memoria, la tabla de multiplicar.

Vivencias como las recién mencionadas suelen ser castradoras y, según Caballero-Jiménez y Espínola-Reyna (2016), generan ansiedad en los estudiantes, los cuales irradian importantes rechazos hacia las matemáticas y hacia quienes enseñan esos contenidos. Otros casos también muestran preocupantes niveles de desatención a los estudiantes, quienes no siempre reciben respuestas a sus interrogantes, generándose así una serie de elementos que pueden ser causantes de incompetencias aprendidas e inscritas en "la errada creencia de que no se es capaz de lograr algo, independientemente de que ese algo pudiera no tener alguna dificultad en sí” (Martínez-Padrón, 2021, p. 92). 
$\mathrm{Al}$ amalgamar estas incompetencias aprendidas con las matemáticas, Martínez-Padrón (2021) las concibe como incompetencias matemáticas aprendidas, producto de no poseer las competencias o pericias demandadas para emprender tareas exitosas donde haya que utilizar contenidos conceptuales, procedimentales o actitudinales ligados a las matemáticas. Se rigen según la postura de indefensiones aprendidas delimitadas por Seligman (2006), en concordancia con las incompetencias aprendidas singularizadas por Flores (2013), quien las declara como parte de una anomia asiliente, por cierto, muy bien ejemplificada en la historia del águila Eva (Flores, 2014), donde hace alusión al impacto que puede ocasionar el hecho de no hacer nada ante lo adverso, a consecuencia de, por ejemplo, una creencia errónea. Por tanto, quienes poseen estas incompetencias tienden a no estar prestos al desarrollo de las tareas o se niegan a desplegar las potencialidades necesarias para resolver los problemas matemáticos que se le planteen (Broadwell, 1969; Martínez-Padrón, 2008, 2016, 2021), a pesar de saberse, según Cyrulnik (2018) y Flores (2013), que todo sujeto nace resiliente y, por tanto, capaz de afrontar cualquier adversidad que se le presente en estas situaciones.

La presencia de anomia asiliente, conjeturada por Flores (2013) y presente en individuos que tienen ideas distorsionadas y descaminadas de la norma, tanto de sí mismo como de sus competencias, colapsan, inhiben, bloquean o fragilizan las actuaciones requeridas para resurgir ante lo adverso. Tal autor alerta que la transformación sistemática de factores como valores y creencias, así como la creación de mitos (Martínez-Padrón, 2013a), han evolucionado, lamentablemente, de generación en generación, logrando conquistar una gran anomia donde aspectos como la sumisión, el desapego y el abandono de lo que les pertenece prevalece y sigue marcando una preocupante pobreza mental observable en quienes tienen falta de organización y compromiso. En estos casos, sus protagonistas terminan disfrazando sus vidas para simular otras que en nada le benefician en relación con las circunstancias. Por tanto, exhiben actitudes negativas y enfermizas que no ayudan a deslastrarse de las conductas desfavorables.

Sobre la base de las aseveraciones anteriores, la acepción de la anomia asiliente es contraria a los procesos resilientes que se mencionarán luego, dado que la primera puede derivarse de situaciones de exclusión, violencia o de marginación de sujetos (Flores, 2013). Este mismo autor sostiene que los sujetos que padecen de anomia asiliente transforman la visión real de sí mismo en una incompetencia aprendida que no les permite entender cómo hacer algo, así como tampoco reconocer su déficit.

En este orden de ideas, la no consideración de, por ejemplo, las ideas previas a la clase y el ignorar las capacidades de los aprendices en el momento del desarrollo de las tareas matemáticas suele marcar unos niveles de dependencia que en nada benefician la adquisición de competencias matemáticas por parte de los estudiantes (Broadwell, 1969). Al contrario, mutila las posibilidades de emprenderlas y de eso no solo hay responsabilidades compartidas de los docentes que enseñan matemáticas, sino de los padres o tutores que consideran, en muchos casos, que lo que más interesa es que el aprendiz apruebe el curso bajo cualquier circunstancia, no importando mucho si se aprenden o no los contenidos previstos en la malla curricular. Si a eso se le agrega que, por tradición, "se privilegia lo estrictamente intelectual en 
detrimento de la carga afectiva que pudiera servir para explicar, describir o comprender lo que acontece, con frecuencia, en las aulas de clase de Matemática” (Martínez-Padrón, 2016, p. 37), entonces no resulta extraño encontrarse con condiciones de fracaso escolar, sobre todo cuando existen tutores que solo se preocupan porque sus representados obtengan buenas calificaciones, "en desmedro de lo que aprendió... $<<$ ¡Si obtuvo buena calificación, el resto no importa!>>” (p. 38).

En este transitar, siempre salen a flote las competencias que se desarrollan, o no, durante la clase, así como las incompetencias inconscientes y conscientes que señala Broadwell (1969) en las fases de aprendizaje observadas en sujetos, las cuales son acoplables a cualquier contenido como el matemático. Respecto a la fase de incompetencia inconsciente, dicho autor precisa que advienen justo cuando el sujeto ni siquiera tiene consciencia de lo que sabe. Por tanto, cuando ocurren sus actuaciones como consecuencia de lo aprendido, éstas suelen ser deplorables. Pero, si estas incompetencias se hacen conscientes, por autocuestionamiento o como consecuencia de la objeción de otros, se reconoce su presencia y pasan a ser incompetencias conscientes. Si luego se interviene y se insertan los elementos resolutorios de la situación desfavorable, pasan a formar parte de las competencias conscientes de los sujetos, cerrando el ciclo con una nueva fase de competencias inconscientes que se materializa al hacerse rutina en el uso de la competencia.

Puede observarse que las dos primeras fases de incompetencias advertidas por Broadwell (1969) pueden aliarse con la ausencia de resiliencia matemática en los potenciales aprendices, abriendo senderos para cambiar, hacia lo favorable, las incompetencias matemáticas aprendidas en las experiencias de aprendizaje llevadas a cabo durante las clases, tanto para los que aprenden como para quienes enseñan.

Revisar un ejemplo dado por Broadwell (1969), sobre las incompetencias inconscientes y conscientes, resulta oportuno dado que alude la actuación de una maestra caracterizada por procederes didácticos pobres, pero que no lo sabe y, por ende, está minada de ejecuciones docentes que resultan monótonas y aburridas para los estudiantes, no permitiendo conquistar la atención de sus aprendices. De igual manera, tampoco abre espacios para germinar, desarrollar o reforzar nuevos aprendizajes. El hecho de lograrse resultados negativos, que no están en sintonía con la materialización de resultados satisfactorios, es considerado como una muestra de incompetencias aprendidas, mayormente inconscientes, detentadas por docentes que no siempre se dan cuenta de que esa ausencia de logros no solo depende de los aprendices, sino de su manera de desarrollar las actividades didácticas. Broadwell asienta que existen docentes que no parecen preocuparse por tal situación y se conforman con reportar bajo rendimiento en sus estudiantes, denotando así despreocupación por el impacto que esto causa en los estudiantes, a pesar de ser una actuación capaz de propiciar fatalidades. No obstante, existen otros que experimentan situaciones similares, pero hacen consciente esa incompetencia, abriendo espacio para aprender nuevas habilidades que permitan cambiar esta realidad hacia el mejoramiento.

Broadwell (1969) es claro al decir que mientras ese tipo de docentes no hagan consciente esa incompetencia, no se puede hacer nada para mejorarle, pero, si se alerta, se tendría a un docente con 
carencias, pero afortunadamente reconocidas. Lo ideal es que ese nivel de conciencia de la incompetencia aprendida permita buscar y encontrar posibilidades para mejorar los métodos empleados, logrando que se haga, de tanto ensayarlos, una competencia inconsciente.

Bajo estas circunstancias, ha de ponerse en escena un proceso que Cyrulnik (2018) denomina resiliente percibido desde el instante de dar cara a eventos adversos o traumáticos vividos en momentos particulares, hasta la gestación de un nuevo desarrollo. En ese ámbito psicológico, Chmitorz et al. (2018) aseguran que la resiliencia se considera, cada vez más, como un resultado donde el individuo se recupera a pesar del infortunio que debe arrostrar, siendo la exposición al riesgo un requisito primordial. Por tanto, la resiliencia de un sujeto solo puede determinarse si al inicio del proceso estuvo sometido a eventos hostiles o funestos que luego superó, conjugándose entonces múltiples factores no solo internos que forman parte, por ejemplo, de sus rasgos de personalidad y de su identidad, sino externos como los protectores, asumiendo que estos factores protectores constituyen mecanismos, condiciones o entornos capaces de favorecer el desarrollo tanto de los sujetos como de los grupos donde se adscribe (HarringtonMartínez, 2016). Por tanto, liberan o reducen los riesgos que pudieran afrontar los sujetos. Tal es el caso del apoyo que puede suministrar la familia o los docentes al momento que los estudiantes deben dar cara a las adversidades.

Creencias, actitudes y estados emocionales son algunos de los factores internos, aludidos por Chmitorz et al. (2018), que participan en la modificación de respuestas en los sujetos, pero también mencionan la intervención de factores externos como los entornos estables y ricos en recursos partícipes en ese proceso dinámico y enrutado por trayectorias de ajuste y recuperación de un proceso perturbador. Bajo estas condiciones, la resiliencia no suele lograrse de manera instantánea, sino que solicita tiempo para crecer y restaurar lo deseado.

Windle (2011) plantea que la resiliencia y la vida normal están entrelazadas. Sostiene que todo ser humano tiene la condición de ser resiliente, a pesar de afrontar los riesgos y adversidades sustanciales de la vida. Pero, para que ese proceso resiliente se materialice, se hace necesario explorar lo subyacente a la adversidad y aprovechar las potencialidades que existen tanto en el mismo sujeto como en su entorno inmediato. Por eso, la resiliencia está asociada con la capacidad de renacer o resurgir después de afrontar adversidades y superarlas, teniendo claro que no es algo que se tenga o que no se tenga, pero puede cultivarse y promocionarse, de manera que dicha capacidad sobreviene a un período de dolor de ámbito emocional.

El escenario para desarrollar la resiliencia es variado, pero destacan la familia y, en este caso, los docentes que enseñan contenidos matemáticos en las instituciones educativas. Ambos agentes se apuntalan como los factores protectores (Chrysani et al., 2017) más relevantes, en virtud de las interacciones comunicacionales efectivas que deben producirse no solo entre el aprendiz y su docente, sino entre los familiares más próximos o entre los compañeros de clase.

Conjugando algunos referentes mencionados por Cyrulnik (2003, 2018), Flores (2013), Goleman y Senge (2016), Johnston-Wilder y Lee (2014), Lee y Johnston-Wilder (2017), Martínez-Padrón (2021) y 
Wolin y Wolin (1993), entre los pilares fundamentales de la resiliencia destacan los siguientes: iniciativa, creatividad, confianza en sí mismo, independencia, tolerancia a la frustración, responsabilidad, valoración, afrontamiento y la identidad del resolutor, visionando este último constructo en relación con quien resuelve o soluciona un problema o una dificultad que se tiene respecto a una situación.

En el caso de la escuela, se hace necesario desarrollar las bases acopladas tanto a factores internos como externos, haciendo posible la disposición de herramientas, medios y recursos para que el aprendiz de contenidos, no solo matemáticos sino de cualquier tipo, de cara al tropiezo que pudiera representar el problema a resolver, el cual es ineludible en cualquier situación de clase de cursos de matemáticas basados en problemas. ¡Sobreponerse de manera positiva es la meta! (Martínez-Padrón, 2016, 2021). Si el obstáculo, según los estudiantes, es un problema matemático sentido como una situación extrema, prevalece salir a su encuentro no solo con recursos como los psicológicos, sociológicos y culturales que posee el aprendiz, sino con los conocimientos matemáticos previos que tenga disponibles o sean rescatables en ese momento, circunstancia o contexto particular. Además, debe contar, en lo posible, con las contribuciones que pueden dar los factores protectores ligados a su entorno. Esto debe concretarse no como una suma de partes sino como aspectos que se imbrican entre sí y conforman la complejidad vivencial del aprendiz (Ávila, 2018).

Por eso, afrontar descalificaciones, intimidaciones, hostilidades y otras castraciones que amenazan el buen desarrollo de las competencias matemáticas deseadas es una necesidad impostergable y debe ser asumida con urgencia, no solo por los aprendices sino por los que enseñan matemáticas. Las huellas dejadas en el proceso de enseñanza-aprendizaje-evaluación de contenidos matemáticos son producto de un conocimiento profesional muchas veces frágil para atender lo que va más allá de lo cognitivo (García-González \& Martínez-Padrón, 2020). Por tanto, toda labor docente, en vez de sortear estas situaciones, debería apostar a generar sujetos plenos de pericias para resolver cualquier problema que se le presente en su cotidianidad o en otros escenarios que precisen del uso de sus potencialidades.

Gran parte de ese resurgir de muchos estudiantes, de los que ya aprendieron a ser matemáticamente incompetentes, a consecuencia, por ejemplo, de la manera como son tratados en la clase de matemáticas (Martínez-Padrón, 2013b, 2016, 2021), debe estar afiliado a una labor docente que trascienda lo cognitivo y tome en cuenta otros factores como los afectivos, culturales, contextuales, biopsicosociales y políticos, en virtud de que pueden enrarecer el clima de la clase y, por ende, el de sus protagonistas. Se visiona, entonces, una referencia a los que siguen enseñando matemáticas de manera tradicional, los cuales prefieren culminar sus programas a como dé lugar, antes que atender lo que acontece en sus potenciales aprendices (MartínezPadrón, 2013a, 2013b, 2016), habida cuenta de que en el aula se comparten responsabilidades en cuanto al desarrollo de los pilares fundamentales de la resiliencia.

Todas estas falencias se profundizan en estos tiempos de pandemia donde, por necesidad, se cambiaron aulas tradicionales por virtuales, gestándose así una nueva situación problemática que precisa, a estos mismos actores, mantener una dinámica para lo cual no siempre están preparados. Según 
la IEA-E y UNESCO-E (2020), en las encuestas aplicadas por TIMSS 2019, organización que tiene la misión de estudiar las tendencias y progreso en matemáticas y ciencias en el mundo, no solo se detectó la necesidad de atender lo referido a la capacitación y formación de los docentes en servicio en función de sus necesidades críticas, sino mejorar "las normas de formación docente inicial" (p. 4), lo cual es un llamado a mejorar la calidad de la formación de los docentes. TIMSS 2019 hace saber que si se quiere lograr éxito educativo es imprescindible tomar en cuenta los factores socioemocionales, haciendo necesario abordar cuestiones motivacionales, de seguridad y confianza en los estudiantes. En este sentido, los docentes deben motivar a los estudiantes haciéndoles saber que sí pueden, aunque ellos piensen que no es así (IEA-E \& UNESCO-E, 2020).

El llamado a cambiar la manera de enseñar matemáticas es urgente, siendo la pandemia una clave para concretar partes de estos cambios. Delgado (2020) sostiene que, para mejorar la academia en estos tiempos de crisis, los docentes deben tomar en cuenta las diferencias sociales, las posibilidades de servicios comunicacionales y los factores emocionales, entre otros aspectos. Además de urgir no fomentar ni exacerbar las desigualdades existentes. Este autor agrega que el docente debe tomar en cuenta los tiempos, momentos y ritmos de aprendizaje, sin olvidar que no todos tienen la posibilidad de concretar sincronías en los horarios estipulados. Por tanto, no podemos seguir atados al modelo de clases tradicionales por éstas estar regidas, normalmente, por un molde donde el docente siempre expone, mediante una clase magistral: tipo conferencia, una serie de temas matemáticos que el estudiante debe memorizar, reproducir y mecanizar para dar cuenta de su saber en las evaluaciones correspondientes (Collí et al., 2020).

En correspondencia con esa limitación, Collí et al. (2020) indican que, por la situación pandémica actual, las experiencias de aprendizaje deben desprenderse de la tradicionalidad puesto que éstas ahora son mediadas por la tecnología y apoyadas, normalmente, en aulas virtuales, aunque reconocen que eso limita o suprime la interacción cara a cara estudiantes-estudiantes y docente-estudiantes. Aún no se sabe si mediante el uso de aulas virtuales realmente se limita el desarrollo de competencias matemáticas propias, sobre todo por las dificultades y restricciones que se tienen para: (a) observar lo que acontece durante el proceso de adquisición de conocimientos y producción de saberes matemáticos; (b) abordar procesos de significación, a la luz del contexto de los grupos socioculturales atendidos; $\mathrm{y}$ (c) hurgar estados emocionales y la manifestación de creencias y actitudes hacia las matemáticas.

El reto por cambiar el proceso de enseñanza-aprendizaje-evaluación de los contenidos matemáticos, hacia el mejoramiento, sigue en suspenso aunque ya está claro que las clases no deben limitarse a la simple digitalización de los contenidos disciplinarios ni acoplarse a la producción de videos que contengan las mismas clases magistrales que luego se divulgan de manera sincrónica o asincrónica, pues, seguirían enclavadas a la tradicional desconexión con el contexto y con la realidad de los estudiantes (Barrón-Tirado, 2020). A tal efecto, Collí et al. (2020) advierten sobre la necesidad de abandonar esta tradición, propendiendo buscar, de una vez por todas, herramientas y recursos que permitan obtener aprendizajes significativos y vivenciales. Siendo así, es muy probable que los aprendices de contenidos 
matemáticos dejen de aburrirse en la clase de matemáticas, sobre todo cuando se sabe que esta emoción es una de las más experimentadas en el aula (Hannula, 2020). En este sentido, hay que aprovechar las potencialidades de las TIC, el contexto y las variadas herramientas y recursos que se disponen en la red, aunque eso limite la posibilidad de observar, a plenitud, tanto lo que acontece en el desarrollo de la clase como la dinámica interaccional que ocurre, transcurre y discurre entre sus protagonistas.

Aunque se siguen haciendo investigaciones que proponen nuevas técnicas, estrategias y recursos, así como se han realizado transformaciones e innovaciones curriculares, el problema del aprendizaje de las matemáticas sigue vigente y eso se debe al hecho de sesgar lo que se investiga al campo cognitivo o a la sola identificación y medición de variados factores del ámbito afectivo. Preocupa que son muy pocos los casos donde se hacen abordajes que permitan sostener alternativas para cambiar sistemas de creencias y actitudes, o explorar estrategias individuales de regulación de estados emocionales que impacten en el mejoramiento de lo que acontece en el aula de matemáticas (Hannula, 2020). Tal autor agrega que no sucede lo mismo cuando se habla de la caracterización de aulas donde se optimice el clima emocional, sobre todo cuando existen retroalimentaciones positivas y se satisfacen las necesidades de los aprendices.

Lo anteriormente planteado convoca a que este tipo de investigaciones sea una práctica ubicua y propiciatoria de un robustecimiento del conocimiento profesional de los que enseñan contenidos matemáticos, el cual debe contemplar la adquisición de competencias para orquestar y conducir procesos relacionados con el conocimiento emocional ya mencionado por García-González y Martínez-Padrón (2020). Intervenir en esos procesos donde se pueda hablar de traumas, bloqueos, dolor, miedo, ansiedad o aversión hacia las matemáticas es imprescindible siempre que se quiera amainar o eliminar la anomia asiliente que suele imperar en las aulas de matemáticas (Flores, 2013; Martínez-Padrón, 2016, 2021).

A lo largo del discurso se puede observar que todo lo discutido gira en torno a las matemáticas y a la resiliencia con sus temas afines. En este sentido, es oportuno declarar que la resiliencia necesaria para aprender matemáticas es denominada Resiliencia Matemática (Johnston-Wilder \& Lee, 2014) y en ese constructo se entrelazan diversos factores cognitivos, afectivos y sociales, sin excluir el contexto, modelos de enseñanza, recursos, necesidades y las particularidades de los aprendices, lo cual la certifica como un proceso complejo, pero necesario y urgente de desarrollar, para cuando se quiere cambiar lo que ocurre, transcurre o discurre en las actuales aulas de matemáticas.

Para Schoenfeld y Arcavi (2020) resultaba extraño pensar que la política fuera una traba para construir sentido en el aula de matemáticas, pero con el tiempo le dieron espacio al notar las limitaciones y obligaciones que marcan los alcances curriculares apuntalados desde la noosfera, dado que, a veces, no permiten que se pongan en marcha determinados procesos, así se tenga la intención y las competencias para configurar un buen contingente de resilientes matemáticos. Por tanto, eso también hace que la resiliencia no pueda erigirse de la manera deseada.

Se conjetura que para poder edificar la resiliencia matemática en los aprendices es plausible tomar en cuenta la construcción de sentido (sensemaking), asumiendo este constructo como un proceso social, 
interactivo y situado a través del cual las personas conexionan ideas, problemas, estrategias, conceptos o argumentos que nos son nuevos, y hasta misteriosos, "con lo que ya sabemos, de manera que disipe una inconformidad intelectual, resuelva contradicciones percibidas, y genere nuevo conocimiento que nos proporciona una sensación de satisfacción y logro” (Schoenfeld \& Arcavi, 2020). Siendo así, se requiere yuxtaponer la construcción de sentido con la aventura de emprender la resolución de cualquier problema matemático, lo cual convoca la necesidad de explorar ideas, conectarlas y encajarlas, críticamente, con el bagaje de conocimientos que se trae consigo. De seguida, la posibilidad de resolver las contradicciones percibidas debe acrecentarse, generando así nuevos y trascendentes conocimientos, abrigados, como lo dice Polya (1965), de sensaciones de esperanza, satisfacción, placer y logro.

Schoenfeld y Arcavi (2020) agregan que generar equilibrio, donde antes había una incomodidad intelectual, a veces resulta cuesta arriba, sobre todo cuando existen casos de docentes que parecen esperar la entrega de recetas que funcionen en todo momento y contexto, no teniendo claro que los protagonistas de la clase poseen sus particularidades y eso se relaciona con las ideas planteadas por Richardson et al. (1990), quienes aseveran que no todos afrontamos determinada situación de la misma manera, así como tampoco todos podemos ser dañados o salir indemnes por la misma adversidad.

La resiliencia matemática que se aspira debe corresponderse con el desarrollo y optimización de una competencia que se materialice cuando se arrostran, con dedicación, confianza, interés, responsabilidad y persistencia, determinados quehaceres matemáticos que pueden pensarse como escollos, logrando luego salir airosos de la situación. En consecuencia, la fuerza de trabajo frente a todo lo que sea visto como dificultad debe estar investida de voluntad y reflexión, hasta superar las barreras que pudieran presentarse en el desarrollo de actividades ligadas a determinados objetos matemáticos que, en ese momento histórico, pudieran tener un carácter hostil o representar una piedra en el camino (Martínez-Padrón, 2016, 2021).

Ha de tomarse en cuenta que, cuando se actúa de manera resiliente, una de las reacciones que la conforman es la capacidad de resolver la adversidad y no pelear contra ella, pues emanan respuestas diferentes (Flores, 2013). Por eso se habla de afrontar la adversidad, lo cual está muy conectado con algunas particularidades como autonomía, autodeterminación, tomar decisiones, tener criterios propios y estar libre de miedos para lograr lo que nos proponemos en nuestro desarrollo (Flores, 2013). Siendo así, se aspira una sana interdependencia que admita afrontar adversidades con autonomía.

Por supuesto que, cuando se trata de una clase de matemáticas, el escenario más expedito para desarrollar procesos resilientes es la misma institución educativa donde se desarrolla la clase y en ella se debe contar con la participación activa de sus protagonistas. También, el seno familiar y otros agentes extrafamiliares son preponderantes para el desarrollo de procesos resilientes (Harrington-Martínez, 2016), siendo saludable una buena relación del aprendiz con los agentes de su entorno: padres, docentes, compañeros de clase, entre otros. 
Vale resaltar que, en las últimas décadas, se han venido haciendo investigaciones sobre Educación Matemática donde el desarrollo de la resiliencia matemática juega un rol protagónico (Ariyanto et al., 2017; Johnston-Wilder \& Lee, 2010, 2014; Johnston-Wilder et al., 2015; Lee \& Johnston-Wilder, 2017).

Johnston-Wilder y Lee (2014) mencionan que la resiliencia ha venido edificándose con apoyo de profesores de escuelas. En este caso, lo hacen en tres escuelas donde capacitaron a los estudiantes para que adquieran una postura reflexiva dirigida a abordar a las matemáticas con persistencia hacia la dificultad y con confianza hacia la materialización de un trabajo exitoso. Concretar esta construcción positiva ayuda a los aprendices a superar barreras, entre ellas, la eliminación de actitudes negativas hacia las matemáticas; por eso, en el programa puesto en escena, la meta era que los estudiantes usaran las matemáticas más allá de la escuela, en lugar de simplemente aprobar los exámenes. Por tanto, les interesaba que los estudiantes desarrollaran las habilidades necesarias para funcionar, como lo dicen los autores, matemáticamente.

Tales autores centraron su atención en el enfoque de enseñanza utilizado, el cual permitió ensayar habilidades aisladas mediante un aprendizaje activo donde los estudiantes, entre otras actividades, no solo tenían que producir videos donde pudieran probar sus ideas matemáticas y vincularlas, sino producir dramas realistas en los cuales usaran las matemáticas, de manera funcional, en contextos particulares, asumiendo que esta funcionalidad atiende, según una de las acepciones de la RAE (2021), no solo la utilidad de los contenidos matemáticos aprendidos sino su eficacia.

Utilizando datos recopilados de entrevistas aplicadas tanto a docentes como a sus estudiantes, diarios escritos por los estudiantes y notas de campo registradas por los investigadores, Johnston-Wilder y Lee (2014) consideran que marcaron diferencias favorables en el aprendizaje de las matemáticas, valiéndose de cuestionarios que permitieron medir los cambios.

En este orden de ideas, Ariyanto et al. (2017) centraron su atención en la resiliencia de futuros docentes de matemáticas, inspirándose en la mejora de capacidad de recuperación de estos estudiantes, después de ser tratados a través del método de aprendizaje basado en problemas, todo en función de sus conocimientos elementales y generales sobre las matemáticas. Los autores aseveran que los futuros profesores de matemáticas deben desarrollar actitudes adaptativas positivas hacia esa asignatura, a fin de continuar aprendiendo matemáticas, a pesar de tener que lidiar con obstáculos y dificultades. Entre los hallazgos destacan que hay una mejora en la capacidad de recuperación de los futuros maestros después de recibir tratamiento mediante el aprendizaje basado en problemas, indicando que uno de los factores que causan la mejora de su resiliencia dependió de lo que ellos escribieron ante las dificultades que tuvieron para resolver los problemas matemáticos dados y lo que hacían para superarlos.

Johnston-Wilder y Lee (2010), Johnston-Wilder et al. (2015) y Lee y Johnston-Wilder (2017) también reportan información de interés para el desarrollo de resiliencia matemática en estudiantes, destacando estos dos últimos autores sobre la necesidad de crearles una cultura de que sí son capaces de resolver cualquier problema de matemáticas, a pesar de los escollos que pudieran encontrarse en el 
camino. Por tanto, es imprescindible dar cara a esos obstáculos y demoler todos esos muros que no permiten lograr el éxito deseado por los protagonistas de la clase. Los autores mencionados en esta sección advierten que cuando los estudiantes se empoderan de la resiliencia matemática correspondiente se colman de suficientes pericias para deslastrar actitudes negativas y estados emocionales desfavorables, tales como la aversión y la ansiedad.

\section{A MANERA DE CIERRE}

Las emociones desempeñan un papel fundamental en los seres humanos. Desde una perspectiva cognitiva, éstas nos permiten evaluar situaciones y nos predisponen a la acción. Por tanto, las experimentamos día a día en cada actividad o rol que desempeñamos, y el aula de clases no es la excepción. Nadie mejor que la propia persona para conocer las situaciones que le desagradan y aquellas que disfruta; sin embargo, no siempre se es capaz de dar la palabra adecuada a ese disfrute o desagrado, es decir, no somos capaces de expresar la palabra emocional que mejor describe lo que sentimos, a pesar de que experimentamos esa emoción. De ahí que se vuelve importante la adquisición de conocimiento emocional, por medio de las habilidades que se mencionan en este escrito. Conocer lo que nos hace sentir bien de lo que nos hace sentir mal nos puede ayudar a buscar la manera de regular las emociones negativas, por medio de la modificación de la situación desencadenante de lo que nos provoca el malestar.

La importancia de conocerse emocionalmente, tanto si se es estudiante como si se es docente, repercute en el bienestar propio y en las relaciones que podamos entablar; por ejemplo, con los saberes que aprendemos y enseñamos, con los compañeros de clase o de trabajo, así como entre profesor y estudiante. Por ello, resulta favorable desarrollar en las clases de matemáticas el conocimiento emocional (García-González, 2020; García-González \& Martínez-Padrón, 2020), teniendo claro que dichas clases están ceñidas a un proceso cognitivo y afectivo donde sus protagonistas piensan, se aventuran, aplican y comunican, de manera significativa, ideas, conceptos, procedimientos y relaciones entre las entidades involucradas en los problemas matemáticos que pudieran plantearse.

Pero, al mismo tiempo, con una mirada compleja del conocimiento humano surge un importante desafío, a saber, el abrirse a las incertidumbres y limitaciones del conocer. Por ejemplo, cabe preguntarse: ¿siempre tendrá sentido aspirar a encontrar una situación desencadenante de una u otra emoción?, ¿se trata acaso de una relación lineal e implicativa entre la díada situación/emoción? Dado el entrecruzamiento de nuestras emociones con múltiples facetas y momentos que las hacen emerger, de manera inseparable y entretejida a la complejidad vivencial de cada sujeto aprendiz/enseñante de matemáticas, es bastante plausible abrirse a la posibilidad que no siempre se trata de una relación lineal.

De manera que, adentrarse a escudriñar de manera sensible y profunda en la ocurrencia de una emoción, aún sin aspirar a dilucidar sus causas (o inclusive a nombrarla), sino que explorando en los flujos y configuraciones experienciales que la hacen emerger, pensamos que propiciaría un desarrollo de la comprensión y un acercamiento más empático entre los actores del aula de matemáticas. Las emociones se 
asemejan más a un mar que se desborda que a una estructura que puede ser desbordada por ese mar; forman parte de nuestra naturaleza no siempre decodificable como seres humanos que somos.

Así, entre las potencialidades y limitaciones acerca del estudio de los fenómenos emocionales, esperamos sentar la reflexión para atreverse a problematizar y seguir explorando en ella. Al respecto, queda un amplio camino por recorrer; podemos, por ejemplo, situarnos en la regulación, la comprensión, la valoración o en la ocurrencia de una emoción. Todas éstas y otras tantas que puedan develarse para su estudio en Educación Matemática, vemos relevante que entren a escena en las discusiones que se dan al interior de la disciplina, desde una mirada de la complementariedad y entrecruce de aproximaciones. En tal sentido, coincidimos que es urgente atender a las emociones en el aula de matemáticas, tomando en cuenta sus componentes personales, sociales, culturales, fisiológicas, etc., dado que están en y con nosotros en todo momento de nuestras vidas.

A la vez, se espera haber subrayado en este escrito que la construcción de sentido y la resiliencia matemática son dos procesos que se reclaman, se auspician, se gestionan, se traslapan y hasta se amalgaman en un solo ente, habida cuenta de que con ambos constructos se facilitan sensaciones de logro y disfrute por la actividad intelectual que debe llevarse a cabo entre los protagonistas de la clase, en vista de estar comprometidos con la idea del ¡sí se puede! Dado que ambos procesos, intrínsecamente, se legitiman y se cobijan, no hay que despreciar lo que pudieran tributar los factores protectores apuntalados por los familiares más próximos y por el apoyo extrafamiliar, en este caso representado por los docentes de matemáticas y los compañeros de clase, evitando mientras sea posible, un aislamiento afectivo que no permita atender las particularidades de los aprendices que habitan en un entorno pleno de significaciones, que no deben obviarse.

Es oportuno ultimar que si decidimos ser docentes de matemáticas es necesario asumir nuestro rol con la mayor plenitud posible, puesto que tenemos la obligación de formar sujetos competentes, sanos, íntegros, felices y, entre otros aspectos, colmados de pericias para dar cara a su realidad y resolver cualquier problema que se le presente en su transitar por la vida.

\section{ACLARATORIAS}

Los autores no tienen conflicto de interés que declarar. El artículo ha sido financiado con recursos propios de los autores.

\section{REFERENCIAS}

Ariyanto, L., Herman, T., Sumarmo, U., \& Suryadi, D. (2017). Developing mathematical resilience of prospective math teachers. Journal of Physics: Conference Series, 895(1), 012062, 1-5.

https://doi.org/10.1088/1742-6596/895/1/012062 
Asociación Internacional para la Evaluación del Rendimiento Educativo \& Organización de las Naciones Unidas para la Educación, la Ciencia y la Cultura, Sector Educación. IEA-E \& UNESCO-E. (2020). Medición de los objetivos mundiales de la educación: la contribución de TIMSS. Biblioteca digital de la UNESCO.

https://unesdoc.unesco.org/ark:/48223/pf0000375119_spa

Auzmendi, E. (1992). Las actitudes hacia la matemática-estadistica en las enseñanzas medias y universitarias. Mensajero.

Ávila, J. (2018). Configuraciones emocionales en estudiantes de profesorado de matemáticas. Un estudio desde la perspectiva del pensamiento complejo [tesis de doctorado, Universidad de los Lagos]. Catálogo de la ULagos.

Ávila, J., \& Díaz, L. (2019). Emociones en Educación Matemática: una mirada con base en el pensamiento complejo. Educação छ̋ Realidade, 44(1), e76639, 1-19.

https://doi.org/10.1590/2175-623676639

Ayebo, A., \& Mrutu, A. (2019). An exploration of calculus students' beliefs about mathematics. International Electronic Journal of Mathematics Education, 14(2), 395-419. https://doi.org/10.29333/iejme/5728

Barrón-Tirado, M. (2020). La educación en línea. Transiciones y disrupciones. En J. Girón (Ed.), Educación y Pandemia. Una visión académica (pp. 66-74). IISUE-Universidad Autónoma de México.

Bisquerra, R. (2009). Psicopedagogía de las emociones. Síntesis.

Broadwell, M. (1969). Teaching for learning (XVI). The Gospel Guardian, 20(41), 1-3.

Caballero-Jiménez, F., \& Espínola-Reyna, J. (2016). El rechazo al aprendizaje de las matemáticas a causa de la violencia en el bachillerato tecnológico. Ra Ximbai, 12(3), 143-161. https://doi.org/10.35197/rx.12.02.2016.09.fc

Callejo, M., \& Vila, A. (2003). Origen y formación de creencias sobre la resolución de problemas. Estudio de un grupo de alumnos que comienzan la educación secundaria. Boletín de la Asociación Matemática Venezolana, 10(2), 173-194. 
Casassus, J. (2015). La educación del ser emocional. Cuarto Propio.

Chmitorza, A., Kunzlera, A., Helmreicha, I., Tüschera, O., Kalischa, R., Kubiaka, T., Wessaa, M., \& Lieba, K. (2018). Intervention studies to foster resilience - A systematic review and proposalfor a resilience framework in future intervention studies. Clinical Psychology Review, 59, 78-100. https://doi.org/10.1016/j.cpr.2017.11.002

Chrysani, A., Kalogerakis, P., \& Katsis, A. (2017). The road to resilience: breaking the cycle of disadvantage. Educational Journal of the University of Patras UNESCO Chair, 4(1), 71-82. https://doi.org/10.26220/une.2785

Collí, S., González, A., \& Pinto, E. (2020). La enseñanza de las matemáticas: una reflexión sobre su transformación necesaria en tiempos de contingencia. Revista de la Universidad Autónoma de Yucatán, 35(277), 16-28.

Cyrulnik, B. (2003). Los patitos feos, la resiliencia: una infancia infeliz no determina la vida. Gedisa.

Cyrulnik, B. [BBVA: Aprendemos Juntos] (2018, 10 de diciembre). Resiliencia: el dolor es inevitable, el sufrimiento es opcional [vídeo]. YouTube. https://www.youtube.com/watch?v= IugzPwpsyY

Damasio, A. (2009). En busca de Spinoza. Neurobiología de la emoción y los sentimientos. Editorial Crítica S. L.

DeBellis, V. A., \& Goldin, G. A. (2006). Affect and meta-affect in mathematical problem solving: a representational perspective. Educational Studies in Mathematics, 63(2), 131-147. https://doi.org/10.1007/s10649-006-9026-4

Delgado, P. (2020, 21 de julio). La enseñanza de las matemáticas requiere una urgente reestructuración, señala nuevo reporte. Observatorio de Innovación Educativa del Tecnológico de Monterrey. https://observatorio.tec.mx/edu-news/ensenanza-de-las-matematicas-covid19

Di Martino P., \& Zan, R. (2001). Attitude toward mathematics: some theoretical issues. En M. Van Den Heuvel-Panhuizen (Ed.), Proceedings of the 25th annual conference of the International Group for the Psychology of Mathematics Education Vol. 3 (pp. 351-358). PME. 
Flores, D. (2013). La resiliencia nómica. Mejor desempeño para una vida más exigente. Instituto Internacional de Investigación para el Desarrollo.

Flores, D. (2014, 5 de diciembre). Prog 0 Introducción 02 parte 1 [vídeo]. YouTube. https://www.youtube.com/watch?v=skT9wr0m2sA

García-González, M. S. (2020). Desarrollo del conocimiento emocional en matemáticas. Uno. Revista de didáctica de las matemáticas, 88(1), 17-23. https://doi.org/10.33010/ie rie rediech.v11i0.726

García-González, M., \& Martínez-Padrón, O. J. (2020). Conocimiento profesional de los profesores de Matemáticas. Educación Matemática, 32(1), 157-177. https://doi.org/10.24844/EM3201.07

García-González, M. S., Ramírez-Gómez, B., \& Navarro-Sandoval, C. (2021). Situaciones que originan emociones en estudiantes de matemáticas. Bolema, 35(69), 39-62. https://doi.org/10.1590/1980$\underline{4415 v 35 n 69 \mathrm{a} 03}$

Goleman, D. (2006). Inteligencia social. La nueva ciencia de las relaciones humanas. Editorial Kairós.

Goleman, D., \& Senge, P. (2016). Triple focus: Un nuevo acercamiento a la educación. Grupo Zeta, Ediciones B.

Gómez-Chacón, I. M. (2010). Tendencias actuales en investigación en matemáticas y afecto. En M. M. Moreno, A. Estrada, J. Carrillo, \& T. A. Sierra (Eds.), Investigación en Educación Matemática $X I V($ pp. 121-140). SEIEM.

Hannula, M. S. (2020). Affect in Mathematics Education. En D. Lerman (Ed.), Encyclopedia of Mathematics Education (pp. 32-36). Springer. https://doi.org/10.1007/978-3-030-15789-0 174

Harrington-Martínez, M. S. (2016). Resiliencia investigativa en docentes de Educación Superior en el contexto de la UPEL Red central [tesis de doctorado no publicada, Universidad Pedagógica Experimental Libertador].

Hidalgo, S., Maroto, A., \& Palacios, A. (2004). ¿Por qué se rechazan las matemáticas? Análisis evolutivo y multivariante de actitudes relevantes hacia las matemáticas. Revista de Educación, Ministerio de Educación y Ciencia, (334), 75-99. 
Johnston-Wilder, S., \& Lee, C. (2010). Mathematical resilience. Mathematics Teaching, (218), 38-41.

Johnston-Wilder, S., Lee, C., Brindley, J., \& Garton, E. (2015, 17 de noviembre). Developing mathematical resilience in school-students who have experienced repeated failure [ponencia]. 8th annual International Conference of Education, Research and Innovation (ICERI2015), Seville, Spain.

Lee, C., \& Johnston-Wilder, S. (2014). Developing mathematical resilience. The Centre for Research in Education and Educational Technology. https://www.m-a.org.uk/resources/downloads/4CMel-Muldowney-Developing-Mathematical-Resilience.pdf

Lee, C., \& Johnston-Wilder, S. (2017). The construct of mathematical resilience. En U. Xolocotzin (Ed.), Understanding emotions in mathematical thinking and learning (pp. 269-291). Elsevier. https://doi.org/10.1016/B978-0-12-802218-4.00010-8

Lewis, G. (2013). Emotion and disaffection with school mathematics. Research in Mathematics Education, 15(1), 70-86. https://doi.org/10.1080/14794802.2012.756636

Martínez-Padrón, O. J. (2008). Actitudes hacia la Matemática. Sapiens, 9(2), 237-256.

Martínez-Padrón, O. J. (2013a). Representaciones sociales en el aula de Matemática. En R. Flores (Ed.), Acta Latinoamericana de Matemática Educativa 26 (pp. 137-145). Comité Latinoamericano de Matemática Educativa.

Martínez-Padrón, O. J. (2013b). Una mirada al fracaso en el aula de Matemática a la luz del afecto. En SEMUR, Sociedad de Educación Matemática Uruguaya (Ed.), VII Congreso Iberoamericano de Educación Matemática (pp. 2856-2863). SEMUR.

Martínez-Padrón, O. J. (2016). ¿Qué dicen los docentes paraguayos en cuanto al afecto en el aprendizaje de la Matemática?: Una mirada desde el Curso Nanduti. Revista UNIÓN, 12(45), 24-43.

Martínez-Padrón, O. J. (2021). El afecto en la resolución de problemas de Matemática. Revista Caribeña de Investigación Educativa, 5(1), 86-100. https://doi.org/10.32541/recie.2021.v5i1.pp86-100 
Martínez-Sierra, G., \& García-González, M. S. (2014). High school students’ emotional experiences in mathematics classes. Research in Mathematics Education, 16(3), 234-250. https://doi.org/10.1080/14794802.2014.895676

Martínez-Sierra, G., \& García-González, M. S. (2016). Undergraduate mathematics students' emotional experiences in Linear Algebra. Educational Studies in Mathematics, 91(1), 87-106. https://doi.org/10.1007/s10649-015-9634-y

McLeod, D. B. (1992). Research on affect in mathematics education: a reconceptualization. En D. A. Grouws (Ed.), Handbook of research on mathematics learning and teaching (pp. 575-596). Macmillan.

Middleton, J., Jansen, A., \& Goldin, G. (2018). The complexities of mathematical engagement: motivation, affect, and social interactions. En J. Cai (Ed.), Compendium for Research in Mathematics Education (pp. 680-712). National Council of Teachers of Mathematics.

Morín, E. (1990). Introducción al pensamiento complejo. Gedisa.

Morín, E. (1999). Los siete saberes necesarios para la educación del futuro. UNESCO.

Pehkonen, E., \& Törner, G. (1996). Mathematical beliefs and different aspects of their meaning. ZDM-The International Journal on Mathematics Education, 96(4), 101-108.

Polya, G. (1965). Cómo plantear y resolver problemas. Editorial Trillas.

Quiroga, F. (2001). La dimensión a fectiva de la vida. Servicio de Publicaciones de la Universidad de Navarra.

Real Academia Española. (2021). Diccionario de la lengua española (edición del tricentenario). https://dle.rae.es/

Richardson, G., Niger, B., Jensen, S., \& Kumpfer, K. (1990). The resilience model. Health Education, 21(6), 33-39. https://doi.org/10.1080/00970050.1990.10614589

Schoenfeld, A., \& Arcavi, A. [Seminario Educación Matemática 2020]. (2 de diciembre de 2020). "Sensemaking" en Educación Matemática [vídeo]. YouTube. https://www.youtube.com/watch? $=8 A N g J v Y q f r 8 \& t=3840 \mathrm{~s}$ 
Seligman, M. (2006). Auténtica felicidad. Javier Vergara Editor.

Varela, F. (1990). Conocer. Las ciencias cognitivas: tendencias y perspectivas. Cartografía de las ideas actuales. Gedisa.

Vejar-Barra, M., \& Ávila-Contreras, J. (2020). Emociones de estudiantes de tercer año básico en el contexto de evaluaciones escritas en educación matemática. Paulo Freire: Revista de Pedagogía Critica, (23), 47-68. https://doi.org/10.25074/07195532.23.1652

Windle, G. (2011). What is resilience? A review and concept analysis. Reviews in Clinical Gerontology, 21(2), 152-169. https://doi.org/10.1017/S0959259810000420

Wolin, S. J., \& Wolin, S. (1993). The resilient self. Willard.

Zan, R., Brown, L., Evans, J., \& Hannula, M. (2006). Affect in Mathematics Education: an introduction. Educational Studies in Mathematics, 63(2), 113-121. https://doi.org/10.1007/s10649-006-9028-2

\section{Cómo citar este artículo:}

Martínez-Padrón, O. J., Ávila-Contreras, J., \& García-González, M. S. (2021). Conocimiento emocional, complejidad vivencial y resiliencia matemática. Tres facetas para el afecto en Educación Matemática. Revista Venezolana de Investigación en Educación Matemática (REVIEM), 1(2), e202105. https://doi.org/10.54541/reviem.v1i2.6 
(c) () Copyright (c) 2021. Oswaldo Jesús Martínez-Padrón, Jorge Iván Ávila-Contreras y María S. GarcíaGonzález. Esta obra está protegida por una licencia Creative Commons 4.0. International (CC BY 4.0).

Usted es libre para Compartir — copiar y redistribuir el material en cualquier medio o formato - y Adaptar el documento -remezclar, transformar y crear a partir del material — para cualquier propósito, incluso para fines comerciales, siempre que cumpla la condición de:

Atribución: Usted debe dar crédito a la obra original de manera adecuada, proporcionar un enlace a la licencia, e indicar si se han realizado cambios. Puede hacerlo en cualquier forma razonable, pero no de forma tal que sugiera que tiene el apoyo del licenciante o lo recibe por el uso que hace de la obra.

Resumen de licencia - Texto completo de la licencia 